\title{
Association between adiposity and cardiovascular outcomes: an umbrella review and meta-analysis
}

Min Seo Kim ${ }^{1,2}$, MD, Won Jun Kim ${ }^{1,3}$, MD, Amit V Khera ${ }^{4,5}$, MD, MSc, Hong-Hee Won ${ }^{6}$, $\mathrm{PhD}$

${ }^{1}$ Korea University, College of Medicine, Seoul, Republic of Korea

${ }^{2}$ Cheongsan Public Health Center, Ministry of Health and Welfare, Wando, Republic of Korea

${ }^{3}$ Gangneung Prison Medical Department, Ministry of Justice, Republic of Korea

${ }^{4}$ Center for Genomic Medicine and Division of Cardiology, Department of Medicine, Massachusetts General Hospital, Boston, MA, USA

${ }^{5}$ Cardiovascular Disease Initiative, Broad Institute of MIT and Harvard, Cambridge, MA USA

${ }^{6}$ Samsung Advanced Institute for Health Sciences \& Technology (SAIHST), Sungkyunkwan University, Samsung Medical Center, Seoul, Republic of Korea

\section{*Corresponding author:}

Hong-Hee Won, PhD

Samsung Advanced Institute for Health Sciences \& Technology (SAIHST),

Sungkyunkwan University, Samsung Medical Center, Seoul, Republic of Korea

E-mail: wonhh@skku.edu

Keywords: Umbrella review, meta-analysis, cardiovascular diseases, body-mass index, obesity, adiposity

Category: Umbrella review of systematic reviews and meta-analyses 
medRxiv preprint doi: https://doi.org/10.1101/2020.08.18.20176578; this version posted August 22, 2020. The copyright holder for this preprint (which was not certified by peer review) is the author/funder, who has granted medRxiv a license to display the preprint in perpetuity.

\section{It is made available under a CC-BY-NC-ND 4.0 International license .}

Total word count: 4281

Number of Figures: 4

Number of Tables: 2

This manuscript has been reviewed and approved by all authors.

Min Seo Kim, Won Jun Kim, Amit V Khera, and Hong-Hee Won have no commercial associations that may present a conflict of interest in relation to this manuscript. 


\section{Summary Box}

\section{Section 1: What is already known on this topic}

- Obesity is progressively increasing worldwide and cardiovascular disease (CVD) remains a continued threat to public health.

- Although obesity as a risk factor for various cardiovascular outcomes has been studied for decades, the results from previous studies are heterogeneous, making it difficult for clinicians and policy makers to determine genuine and reliable associations.

- The level of evidence underlying the associations between obesity and CVD remains unknown.

\section{Section 2: What this study adds}

- Only 15 of the 53 reported associations (28\%) between obesity and CVD outcomes are supported with a high level of evidence. While other associations may be genuine, various degrees of uncertainty remain.

- An increase in body-mass index was associated with a higher risk of developing coronary heart disease, heart failure, atrial fibrillation, stroke, hypertension, aortic valve stenosis, pulmonary embolism, and venous thromboembolism; the casual effect of obesity on the incidence of CVD was corroborated by Mendelian randomisation (MR) studies, with the exception of stroke.

- The increase in the risk of all-cause mortality and CVD-specific mortality with adiposity was supported by a high grade of evidence in observational analyses, but the causal effect of obesity on mortality outcomes was not significant in MR studies. 


\begin{abstract}
Objective: To evaluate the strength and certainty of the evidence underlying an association between increased adiposity, as assessed by body-mass index (BMI), waist circumference (WC), or waist-to-hip ratio (WHR) and identify the risk of incident cardiovascular disease (CVD) events or mortality
\end{abstract}

Design: Umbrella review of systematic reviews and meta-analyses.

Data sources: Google Scholar, PubMed, Embase, Cochrane Database of Systematic Reviews, and manual screening of retrieved references

Eligibility criteria: Systematic reviews or meta-analyses of observational studies and Mendelian randomisation (MR) studies that evaluated the association between various obesity-related indices and the risk of developing CVD and/or mortality due to CVD

Data synthesis: Eleven systematic reviews and 53 meta-analyses that investigated associations between obesity and cardiovascular outcomes were included. Results from recently published cohort studies were also incorporated into the existing meta-analyses to update them with more recent data. Thus, the present study compiled all the relevant evidence accumulated to date, encompassing a total of 488 cohorts and over 30 million participants. MR studies were collected to identify any causal relationship between obesity and various CVD outcomes, and to avoid reverse causality. The degree of obesity was measured with BMI, WC, and WHR. The evidence levels of pooled results were graded into high, moderate, low, and very low according to the Grading of Recommendations Assessment, Development and Evaluation framework.

Results: An increase in BMI was associated with a higher risk of developing coronary heart disease, heart failure, atrial fibrillation, stroke, hypertension, aortic valve stenosis, pulmonary embolism, and venous thromboembolism; the study results corroborate the casual effect of obesity on the incidence of CVD, except stroke, based on MR studies. The increase in the risk of developing CVD for every $5 \mathrm{~kg} / \mathrm{m}^{2}$ increase in BMI ranged from $7 \%$ (relative risk [RR], 1.07; 95\% confidence interval [CI], 1.03 to 1.11) for stroke to $49 \%$ (RR, 1.49; 95\% CI, 1.41 to 1.58$)$ for hypertension. The risk of all-cause mortality and CVD-specific mortality increased with adiposity, which was supported by a high grade of evidence from observational analyses; however, the causal effect of obesity on mortality outcomes was not significant in MR studies.

Conclusions: Only 15 out of the 53 associations (28\%) reported for obesity and CVD outcomes were supported with high evidence levels from observational analyses. Although other reported associations might be valid, various degrees of uncertainty remain. The causal effect of obesity on 9 of the 14 CVD-related outcomes was corroborated by MR studies. As obesity is progressively increasing around the globe and because CVD remains a constant threat to public health, it is necessary to understand the gradient of evidence underlying the association between these two clinical entities. Any weak links in the association and causality discovered in this review should be reinforced with further scientific research, while high-certainty associations with established causality should be reflected in clinical practices and health policies. 
Systematic review registration: PROSPERO CRD42020179469.

\section{INTRODUCTION}

Obesity has become a major public health challenge as cumulative evidence suggests that increased adiposity is a causative risk factor for diverse adverse health outcomes, including multiple cancers ${ }^{1}$, diabetes mellitus ${ }^{2}$, gynaecological-obstetric conditions ${ }^{3}$, and cardiovascular diseases (CVD) ${ }^{4-6}$. CVDs account for over two-thirds of deaths attributable to high bodymass index $(\mathrm{BMI})^{7}$, and the consequential health outcomes constitute a major portion of health-related economic burden worldwide ${ }^{8-12}$. Despite countermeasures, the outlook is not favourable, and the incidence of CVD is expected to increase over the next few decades, especially in low- and middle-income countries, as the average BMI increases ${ }^{13}$.

Numerous studies support the association between obesity indices and cardiovascular outcomes, but considerable heterogeneity exists between these studies ${ }^{14}$. The heterogeneity may be attributable to the complex nature of obesity as a mediator-confounder. Obesity can directly impact diseases or syndromes, but is also subject to reverse causality, whereby the presence of disease may influence the $\mathrm{BMI}^{15,16}$. Therefore, any investigation exploring this relationship must also address the direction of this causality. In addition, inherent biases are present in the study design of observational research, such as selection and publication biases, which can potentially inflate the observed effect ${ }^{17-19}$. A recent umbrella review revealed that despite strong claims of increased incidence of cancers with increased adiposity, only 11 $(30 \%)$ of the 36 cancer types showed this association with reliable evidence, with minimal influence of biases ${ }^{1}$.

We conducted an umbrella review of systematic reviews and meta-analyses to appraise the entire context and quality of the vast amount of relevant evidence on the association between obesity indices and CVD. The results from recently published cohort studies were manually incorporated into existing meta-analyses to update previous results, and a total of 488 cohorts and over 30 million participants were integrated for quantitative syntheses. The collective outcomes were stratified into distinct evidence levels to quantify the level of certainty underlying each association and included Mendelian randomisation (MR) studies to minimise reverse causation bias. This work may help to contextualise the magnitude of the association and explicate the causality of obesity on CVD.

\section{METHODS}

\section{Literature search and selection criteria}

We systematically searched Google Scholar, PubMed, Embase, and the Cochrane Database of 
Systematic Reviews for systematic reviews and meta-analyses that investigated the association between adiposity indices and cardiovascular health outcomes, from inception to March 28, 2020. The adiposity indices of interest included BMI, waist circumference (WC), and waist-to-hip ratio (WHR). We used a predefined search strategy outlined in the supplementary appendix, and reference lists of relevant review articles were also screened to retrieve additional studies. Observational studies were also collected to update previous metaanalyses, and MR studies were incorporated to evaluate causality as has been performed in previous umbrella reviews ${ }^{20,21}$. We imposed no restriction on language, but all included studies were written in English. The study protocol is published in PROSPERO (CRD42020179469).

\section{Inclusion and exclusion criteria}

We included systematic reviews and meta-analyses of observational studies, as well as the MR studies that explored the association between obesity indices and cardiovascular outcomes using genetic instruments. We excluded systematic reviews and meta-analyses that evaluated indices other than BMI, WC, and WHR, such as weight loss \%, history of bariatric surgery, and adipose tissue volume, as they can increase heterogeneity and hinder valid synthesis of results. Studies that included patients who underwent percutaneous coronary intervention or coronary artery bypass graft, while assessing the incidence of CVD, and those involving animal experiments or in-vitro results were also excluded.

When there was more than one meta-analysis study on the same topic, we preferentially included the most recent, or the one that comprised the largest number of studies to avoid duplication. For outdated meta-analyses, we incorporated the recently published cohort data into the meta-analysis, calculated the pooled effect sizes, and re-analysed the data for heterogeneity, publication bias, and prediction interval (Supplementary Table 1). When multiple observational or MR studies were conducted with an identical cohort (e.g., UK Biobank), those with the most available information (e.g., dose-response estimates) or those with the more comprehensively adjusted model was utilised for the update.

\section{Data extraction}

Two researchers (MS Kim and WJ Kim) independently searched the existing literature and extracted the data. The titles, abstracts, and keywords of each study were reviewed for inclusion, and any ambiguity was resolved through discussion. The study selection process was recorded using the PRISMA flowchart ${ }^{22}$ (Figure 1).

Data were collected with a predefined template. The following details were obtained from the included systematic reviews and meta-analyses of observational studies: publication year, number of studies included in the meta-analysis, exposures, comparisons, number of cases and participants, study design, model of effect estimation (random- or fixed-effects), 
heterogeneity, and maximally adjusted effect size with 95\% confidence interval (CI) for each component study (Supplementary Tables 1 and 2). The adjustment factors included in the model were also retrieved to determine whether relevant confounders were accounted for. Both categorised (overweight, obese, and severely obese) and continuous (BMI, WC, and WHR) measures were extracted for qualitative synthesis. For MR studies, we extracted data on exposure, sample size, instrumental variable method, genetic instrument $(\mathrm{GI})$, variance $\left(\mathrm{R}^{2}\right)$ explained by GI, and maximally adjusted the effect estimates with 95\% CI (Supplementary Table 3).

\section{Data analysis}

We replicated the meta-analyses in our analytic framework and re-analysed the data to uncover the non-explicit details of these meta-analyses to evaluate the quality of evidence. The following items were considered: effect sizes in both fixed- and random-effects models; heterogeneity among studies that were calculated using $\mathrm{I}^{2}$ metric ${ }^{23}$; the presence of publication bias and small study effect using Egger's tests (significance threshold, $\mathrm{P}<0.10$ ) $^{24}$; p-curve test detecting $\mathrm{p}$-hacking ${ }^{25-28}$; and $95 \%$ prediction intervals, representing the range within which the effect estimates of future studies will lie with $95 \%$ certainty $^{29-31}$. We did not conduct the test for excess significance (TES) as it has not been thoroughly evaluated and is not currently recommended by the Cochrane Collaboration as an alternative to conventional tests of publication bias ${ }^{32}$; indeed, the TES was omitted in numerous previous umbrella reviews $^{33-37}$.

We conducted a pairwise meta-analysis using $\mathrm{R}$ (version 3.6.0) software $^{38}$ for re-analysis and update of previous meta-analyses with recently published observational studies. The results are reported in Supplementary Figures 2-39; further details of the methodology and our analytic workflow for pairwise meta-analysis are described elsewhere ${ }^{39-42}$. For certain phenotypes, such as aortic valve stenosis, that have not been meta-analysed despite a sufficient number of published original studies, we performed our own (de-novo) metaanalyses to pool the effect sizes and increase power. The summary of the effect estimation metric (odds ratio $[\mathrm{OR}]$, relative risk $[\mathrm{RR}]$, and hazard ratio $[\mathrm{HR}]$ ) presented by each study is shown in Supplementary Table 1. To provide a straightforward comparison and synthesize multiple outcomes in a single visualization, as shown in Figures 2-4, we approximated different metrics to equivalent RRs using the guideline outlined by Fusar-Poli et al., ${ }^{43}$ and adapted the approach of coordinating the results with different metrics used in previous metaanalyses $^{445}$ and umbrella reviews ${ }^{20} 46$. Pre-specified subgroup analyses were performed to determine whether the results were affected by BMI categories or sex. We recalculated the dose-response relationship by pooling dose-response estimates from each study in the included meta-analyses if they were presented separately for BMI categories ${ }^{47}$.

The analytic process for MR was identical to that of the meta-analyses of observational studies. Since the reliability of the results of MR studies largely depends on the efficacy of 
GIs, sample size, variance $\left(\mathrm{R}^{2}\right)$, and effect size, we performed a power calculation using a non-centrality parameter framework ${ }^{48}$. For MR studies that did not describe $\mathrm{R}^{2}$, we used the extrapolated variance from other MR studies that used similar or identical genetic variants as instruments for calculation ${ }^{20}$. If there were meta-analyses for MR, we used the pooled effect estimates as the main outcomes rather than selecting a representative MR (Figure 3), and reviewed whether the meta-analyses of MR were properly conducted ${ }^{49-53}$.

\section{Evaluation of the certainty of evidence}

We assessed the certainty of evidence for all reported associations using the Grading of Recommendations Assessment, Development, and Evaluation (GRADE) framework ${ }^{54}$, as has been done in numerous previous umbrella reviews ${ }^{34} 363755$. The GRADE framework accounts for study limitations, imprecision, indirectness, inconsistency, publication bias, large magnitude of effect, and dose-response associations (Supplementary Table 4). The GRADE working group recommends assessing studies as grade 4 (high) for RCTs and grade 2 (low) for cohort studies. However, as RCTs are rarely possible for epidemiological topics, such as obesity, and large prospective cohort studies usually have the highest level of evidence ${ }^{5657}$, we assigned grade 3 (moderate) for large-scale prospective cohort studies and grade 2 for retrospective cohort studies to account for such characteristics of epidemiological research. This modification to the GRADE approach is justified by numerous previous studies that have suggested a differentiation of evidence levels between prospective and retrospective cohort studies $^{5659}$. Imprecision was judged when the sample size was insufficient $(<1000)$ or when the CI was substantially large. When the CI value crossed 1 , a judgement on imprecision was made according to our previous report ${ }^{60}$; if the CI value did not cross 1 , we judged imprecision when the full CI length was wider than 0.5. Indirectness reflects differences in study populations; inconsistency was assigned when heterogeneity measured by the $\mathrm{I}^{2}$ statistic was greater than $50 \%$ for binary outcomes, and greater than $75 \%$ for continuous outcomes, since continuous outcomes are prone to higher heterogeneity than binary outcomes $^{61}$, and the Cochrane Collaboration has a revised cut-off of $\mathrm{I}^{2}>75 \%$ for high heterogeneity ${ }^{32}$. Publication bias was detected when the funnel plot was asymmetrical and the P-value for Egger's test was $<0.10$. A large magnitude of effect was considered when RR values were $>2$ or $<0.5$. A dose-response association was determined for the effect size that showed a proportional increase with adiposity indices. The final GRADE was determined after summation of all accountable biases. The 53 previously reported associations were classified according to the GRADE framework and are presented as evidence maps (Tables 1 and 2).

Although the GRADE framework is effective for assessing risk of biases, it does not account for reverse causation bias, which can be a major confounding factor in our topic of research ${ }^{62}$. Hence, we incorporated MR studies, and reviewed any discordance between observational studies and MR analyses for proper interpretation of the results, as summarised in Table 2. 
Evidence from individual MR studies was assessed with statistical power $(>80 \%)^{63}$. The quality of each systematic review and meta-analysis was assessed using AMSTAR2 ${ }^{64}$, as shown in Supplementary Table 5. We did not examine the quality of the individual cohort studies, since this was conducted by the authors of the included meta-analyses and was beyond the scope of this umbrella review ${ }^{20}$.

\section{Patient involvement}

Neither the patients nor the general public were involved in the design, conduct, and reporting of the present study. No patient was asked to advise on interpretation or writing of the results. The results will be disseminated to the general public through public presentations and the authors' involvement in different charities.

\section{RESULTS}

\section{Literature review}

Of the 16112 studies identified in the reviewed databases, 1322 were eligible for title and abstract review. After excluding 1001 studies that met our pre-specified exclusion criteria, 274 systematic reviews with meta-analyses and 47 MR studies were selected for full-text review. After full-text review, 283 studies were further excluded, and 11 systematic reviews with 53 meta-analyses, including a total of 448 cohort studies and 27 MR studies, were included for final analyses. The process of search and selection is presented in Figure 1. The AMSTAR2 grade was moderate for ten systematic reviews, while that for one review was graded as low (Supplementary Table 5).

\section{Meta-analyses of observational studies}

The 53 meta-analyses of observational studies pooled from 448 cohorts were examined, 35 of which were added during our re-analysis. The reported analyses were categorised into 14 primary outcomes according to the disease entity: six morality outcomes, including all-cause mortality, CVD mortality, coronary heart disease (CHD) mortality, stroke mortality, heart failure death, and sudden cardiac death; and eight incidence outcomes, including CHD, stroke, heart failure, atrial fibrillation, aortic valve stenosis, hypertension, pulmonary embolism, and venous thromboembolism (Table 2).

All but four out of the 53 associations were statistically significant based on the results of the random-effect model (Table 1). The increase in the risk of developing CVD for every $5 \mathrm{~kg} / \mathrm{m}^{2}$ increase in BMI ranged from 7\% (RR, 1.07; 95\% CI, 1.03 to 1.11) for stroke to $49 \%$ (RR, $1.49 ; 95 \% \mathrm{CI}, 1.40$ to 1.58 ) for hypertension (Figure $2 \mathrm{~A}$ ). The increase in the risk of developing CVD in the overweight population (BMI > 25 to $30 \mathrm{~kg} / \mathrm{m}^{2}$ ) than in the reference group with normal BMI ranged from 14\% (RR, 1.14; 95\% CI, 1.10 to 1.18) for CHD to $38 \%$ 
(RR, 1.38; 95\% CI, 1.14 to 1.68$)$ for aortic valve stenosis. The increase in the risk of developing CVD in the obese population $\left(\mathrm{BMI}>30 \mathrm{~kg} / \mathrm{m}^{2}\right.$ ) than in the reference group ranged from $16 \%$ (RR, 1.16; 95\% CI, 1.06 to 1.26 ) for stroke to $124 \%$ (RR, $2.24 ; 95 \% \mathrm{CI}$, 1.92 to 2.61) for pulmonary embolism. The increase in the risk of mortality due to CVD for every $5 \mathrm{~kg} / \mathrm{m}^{2}$ increase in BMI ranged from $5 \%$ (RR, 1.05; 95\% CI, 1.04 to 1.07) for allcause mortality to $49 \%$ (RR, 1.49; $95 \%$ CI, 1.45 to 1.53 ) for CVD mortality (Figure 2B).

The association of CVD outcomes with other adiposity measures, including WC and WHR, demonstrated consistent results with that of BMI (Supplementary Figure 1). The increase in the risk of developing CVD for every $10 \mathrm{~cm}$ increase in WC ranged from $18 \%$ (RR, 1.18; 95\% $\mathrm{CI}, 1.12$ to 1.25 ) for atrial fibrillation to $54 \%$ (RR, 1.54; 95\% CI, 1.31 to 1.81) for aortic valve stenosis (Supplementary Figure 1). The increase in the risk of developing CVD for every 0.1 unit increase in WHR ranged from $8 \%$ (RR, 1.08; 95\% CI, 1.01 to 1.15) for atrial fibrillation to $29 \%$ (RR, 1.29; $95 \%$ CI, 1.13 to 1.47 ) for heart failure (Supplementary Figure $1)$.

\section{MR studies}

A total of $27 \mathrm{MR}$ analyses were identified and classified into 22 outcomes, as presented in Supplementary Table 3. The proportion of variance $\left(\mathrm{R}^{2}\right)$ explained by GI was $1.6 \%$ to $1.82 \%$. Thirteen of the 22 outcomes were supported by a statistical power of greater than $80 \%$. The increase in the risk of developing CVD for every $1 \mathrm{~kg} / \mathrm{m}^{2}$ increase in BMI from MR analyses ranged from $6 \%$ (RR, 1.06; 95\% CI, 1.02 to 1.11 ) for pulmonary embolism to $13 \%$ (RR, 1.13; $95 \% \mathrm{CI}, 1.05$ to 1.21 ) for aortic valve stenosis (Figure 3A). The increase in the risk of developing CVD for every $5 \mathrm{~kg} / \mathrm{m}^{2}$ increase in BMI from MR analyses ranged from $19 \%$ (RR, $1.19 ; 95 \% \mathrm{CI}, 1.03$ to 1.37 ) for CHD to $92 \%$ (RR, $1.92 ; 95 \% \mathrm{CI}, 1.12$ to 3.30 ) for heart failure (Figure 3B). The increase in the risk of dying from CVD for every $1 \mathrm{~kg} / \mathrm{m}^{2}$ increase in BMI from MR analyses ranged from $10 \%$ (RR, 1.10; 95\% CI, 1.01 to 1.19 ) for CVD to $12 \%$ (RR, 1.12; 95\% CI, 1.00 to 1.25) for CHD (Figure 3C).

\section{Subgroup analyses}

The risk of CVD outcomes showed a proportional and dose-dependent increase with a stepup in BMI categories (Figure 4A). Obese men were more prone to unfavourable CVD outcomes than obese women (Figure 4B).

\section{Level of evidence}

Of the 53 meta-analyses that investigated the effect of obesity on CVD-related outcomes, 15 associations (28\%) were supported by high evidence certainty (GRADE), as described in the evidence map (Table 1); these meta-analyses summarised the data for overall population ( $\mathrm{n}=$ $8)$, men $(n=4)$, and women $(n=3)$. A total of 19,15 , and 4 associations were supported by 
moderate, low, and very low certainty of evidence, respectively. All of the biases that we used in appraising the certainty of the grade are described in Supplementary Table 4: inconsistency $(52 \%, 28 / 53)$, indirectness $(0 \%, 0 / 53)$, imprecision $(19 \%, 10 / 53)$, publication bias $(21 \%$, 11/53), large magnitude of effect (4\%, 2/53), and dose-response association (79\%, 42/53). To avoid reverse causation bias, concordance between the results of the observational and MR analyses, in either the direction and/or the statistical significance of associations, was identified and has been summarised in Table 2. The results of this study corroborate the causative effect of obesity on 9 of the 14 CVD-related outcomes; 4 mortality outcomes (allcause mortality, heart failure death, stroke mortality, and sudden cardiac death), and the incidence of stroke had a risk of potential reverse causation bias.

For all outcomes, the shape of the p-curve (the distribution of statistically significant P-values for a set of findings, with right-skewed $\mathrm{p}$-curves suggesting findings that contain evidentiary value) was significantly right-skewed $(\mathrm{P}<0.05)$, indicating no evidence of $\mathrm{p}$-hacking.

\section{DISCUSSION}

This umbrella review paints a comprehensive picture of the existing evidence on the association between obesity and CVD by stratifying each association of obesity and CVD outcomes into distinct evidence levels. Eleven systematic reviews, with 53 meta-analyses, comprising a total of 488 cohorts and over 30 million participants were included herein for quantitative synthesis and quality assessment. As observational studies can suggest an association, but are unable to make claims on causation, MR studies were included to determine causality. Therefore, we provide results from observational studies and MR studies in parallel to contextualise both the magnitude of association and the direction of causality.

\section{Principal findings}

Of the 53 meta-analyses that investigated the effect of obesity on CVD-related outcomes, 15 of the reported associations (28\%) are supported by high evidence certainty (Table 1). While other reported associations might be genuine, various degrees of uncertainty remain. The causative effect of obesity on 9 out of the 14 CVD-related outcomes was corroborated by the results of this investigation; however, 4 mortality outcomes (all-cause mortality, heart failure death, stroke mortality, and sudden cardiac death) and the incidence of stroke have a risk of potential reverse causation bias (Table 2).

An increase in BMI was associated with a higher risk of developing all specific CVDs; incidence of CHD, heart failure, atrial fibrillation, stroke, hypertension, aortic valve stenosis, pulmonary embolism, and venous thromboembolism were all shown to increase with higher BMI, and the results were consistent in MR studies, with the exception of stroke (Figures 2 and 3). In our subgroup analyses, the risk of developing CVD showed a proportional and dose-dependent increase with a step-up in BMI categories, and obese men were more prone 
to unfavourable CVD outcomes than obese women (Figure 4). Association of CVD outcomes with other adiposity measures, including WC and WHR, demonstrated results that are consistent with those for BMI (Supplementary Figure 1).

Increased risk of all-cause mortality and CVD-specific mortality due to adiposity was supported by a high level of evidence from observational studies, but only the association between obesity and CHD mortality was shown to be statistically significant in MR studies (Table 2).

\section{Possible explanations}

For MR analysis, Wade et al. used the polygenic risk score (PRS), comprising 77 single nucleotide polymorphisms associated with BMI as reported in the Genetic Investigation of Anthropometric Traits consortium, as the genetic instrument ${ }^{65}$, and the explanatory power of PRS for obesity was found to be reliable ${ }^{66}$. While there are still limitations to the MR approach $^{67,68}$, it is likely that potential biases are less marked than those of observational studies $^{65}$ as long as the general assumptions for MR are met ${ }^{69}$. Triangulation of different methodologies is essential for inferring definite conclusions with proper causal inference ${ }^{65}$, and the findings from MR studies may add to the current body of evidence implicating obesity as a risk factor for cardiovascular health outcomes.

Of note, all-cause mortality significantly increased with higher BMI in observational analyses, but this relationship was not significant in MR analyses. Such discordance may be explained by the intrinsic limitation of observational studies in managing living confounders. Although a significant association of obesity with all-cause mortality rate was observed in 200 collective cohorts, with adjustment for age, sex, and smoking, this association should be interpreted cautiously as all-cause mortality may involve diverse causes of death, such as pneumonia and trauma, which may have weaker links to obesity. Considering that CVDrelated mortality was significantly high with increased obesity in both observational and MR analyses (Table 2), it is plausible that the observational results of all-cause mortality may have been overestimated by other intermediate or surrogate causes for death in cohorts that are not driven by cardiovascular impairment.

The risk of the incidence of all CVDs, except stroke, was significantly increased with obesity in both observational and MR analyses (Figures 2 and 3). A large number of mediators released by adipose tissue may play key roles in the link between obesity and CVD; adipose tissues release bioactive mediators that influence alterations in lipids, coagulation, fibrinolysis, and inflammation, leading to endothelial dysfunction and atherosclerosis ${ }^{70}$. Atherosclerosis is the principal origin of $\mathrm{CVD}^{71,72}$, and synergistically interacts with hypertension, and both factors aggravate one another ${ }^{71,73}$. It is notable that hypertension was the most vulnerable entity affected by BMI in our analysis; the increase in the risk of developing CVD for every $5 \mathrm{~kg} / \mathrm{m}^{2}$ increase in BMI ranged from 7\% (RR, 1.07; 95\% CI, 1.03 
to 1.11 ) for stroke to $49 \%$ (RR, $1.49 ; 95 \% \mathrm{CI}, 1.40$ to 1.58 ) for hypertension. Other CVDs may be the consequences of atherosclerosis and hypertension, as these entities represent pathophysiological basis and are thus major risk factors for $\mathrm{CVD}^{7274-77}$.

Several MR studies have reported that obesity has no causal effect on stroke ${ }^{78-80}$, and stroke was the least affected entity in our observational analysis (Figure 2). This result is in line with a recent study conducted by Khera et al. in which stroke occurred less frequently than most of other CVDs, such as hypertension and venous thromboembolism, in high BMI-PRS carriers $\left(10^{\text {th }} \text { percentile }\right)^{66}$; this observation probably indicates that the genetic drivers for obesity have a weak causal effect on the development of stroke. The discordance in the results of observational and MR analyses for stroke in our umbrella review may suggest that stroke pathophysiology involves a complex mechanism in which obesity is only a minor part ${ }^{81}$.

\section{Clinical implications and future research}

Obesity is a multifactorial disease that results from interactions between genetics and lifestyle $^{8283}$. The heritability for obesity is known to be around $40 \%{ }^{82} 84$, and the remainder could be explained by lifestyle factors, which suggests obesity as a modifiable risk factor ${ }^{85}$. In this context, the causal effect of obesity on nearly all specific cardiovascular outcomes suggested in this study provides an enthusiastic prospect in which lifestyle modification to reduce adiposity can result in the overall reduction of cardiovascular health problems and substantial health-economic burden ${ }^{86}$. This study supports the assertions that reducing adiposity through interventional approaches, such as bariatric surgery ${ }^{87}$; promotion of educational equality ${ }^{88}$; lifestyle modifications, including healthy diets ${ }^{89-94}$; and increasing physical activities ${ }^{93}$ may provide a better chance of improving one's well-being ${ }^{95}$, even more so than previously expected, by affecting multiple vascular health outcomes. Our results also support the diet and lifestyle recommendation proposed by the American Heart Association $(\mathrm{AHA})^{96}$, and further specify the benefits. Future studies should be conducted to provide empirical evidence of the effect of lifestyle modifications targeted at reducing adiposity on cardiovascular benefits.

\section{Limitations}

This study has several limitations. First, umbrella reviews have intrinsic limitations in that they only focus on existing meta-analyses, and therefore important phenotypes that were not assessed in a meta-analysis level may be overlooked. To minimise the disregard of clinically relevant cardiovascular phenotypes, we independently conducted de-novo meta-analyses for certain CVDs (e.g., aortic valve stenosis) that have not been meta-analysed despite a sufficient number of published original studies. Second, when meta-analyses are outdated, they may provide incomplete conclusions with less power, which may directly affect the analyses of subsequent umbrella reviews. As a countermeasure, we updated 19 meta-analyses of observational studies by incorporating recent reports from 35 cohorts to reflect up-to-date 
conclusions. Third, we did not analyse the effect of being underweight on CVD outcomes. Although lower BMI is known to affect CVD outcomes and constitutes a J-shape curve, this analysis was beyond the scope of this investigation, since our research question mainly lies in how increased adiposity affects CVD outcomes. Although our study is similar to previous umbrella reviews on obesity ${ }^{1,3}$, none of these studies included being underweight in their analyses. Lastly, the value of RR should be interpreted with caution as the equivalent RR was retrieved based on assumptions and approximations. We approximated different metrics to equivalent RRs using Fusar-Poli et al.'s guideline ${ }^{43}$, and adapted an approach of coordinating the results with different metrics used in previous meta-analyses ${ }^{44,45}$ and umbrella reviews ${ }^{20}$, ${ }^{46}$; nevertheless, the equivalent RR may not reflect the actual effect size, and rather should be taken as inferences that allow comparisons of the magnitude of the effect of obesity on different cardiovascular phenotypes and outcomes.

\section{Conclusion}

Although obesity as a risk factor for various cardiovascular outcomes has been extensively studied for decades, only 15 of the 53 reported associations (28\%) were supported with a high evidence level. While other associations could be genuine, various degrees of uncertainty remain. The causative effect of obesity on 9 out of 14 CVD-related outcomes was corroborated by the results of this study; 4 mortality outcomes and the incidence of stroke remained at risk of potential reverse causation bias and requires further clarification. Since obesity is progressively increasing around the globe, and CVD is continually threatening public health, understanding the gradient of evidence behind the associations between these two clinical entities is necessary. The strong associations discovered between obesity and CVD outcomes in this review should be considered in clinical practice and in the formulation of health policies, while any weak links should be reinforced with further scientific research.

\section{Funding}

This work was supported by the National Research Foundation of Korea (NRF) grant funded by the Korea government (MSIT) (No. 2019R1A2C4070496). MS Kim had full access to all the data in the study, and HH Won made the final decision to submit for publication.

\section{Contributors}

MS Kim contributed to the concept and design of the study. MS Kim and WJ Kim identified and acquired relevant trials and extracted data. MS Kim drafted the protocol for this study. MS Kim analysed and interpreted the data. MS Kim wrote the first draft of the manuscript. $\mathrm{HH}$ Won and AV Khera contributed to the interpretation of the data and the critical revision of the manuscript. All authors read and approved the final submitted version.

\section{Competing interests}


All authors have completed the ICMJE uniform disclosure form at www.icmje.org/coi_disclosure.pdf (available on request from the corresponding author) and declare the following: no support from any organization for the submitted work; no financial relationships with any organizations that might have an interest in the submitted work in the previous 3 years; no other relationships or activities that could appear to have influenced the submitted work.

\section{Ethical approval}

Not required.

\section{Data sharing}

Not applicable.

\section{Dissemination declaration}

We plan to disseminate the results to study participants and or patient organisations

\section{Transparency}

The manuscript's guarantors (HH Won) affirm that this manuscript is an honest, accurate, and transparent account of study being reported, that no important aspects of the study have been omitted, and that any discrepancies from the study as planned have been explained.

\section{References}


1. Kyrgiou M, Kalliala I, Markozannes G, et al. Adiposity and cancer at major anatomical sites: umbrella review of the literature. BMJ 2017;356

2. Bellou V, Belbasis L, Tzoulaki I, et al. Risk factors for type 2 diabetes mellitus: An exposure-wide umbrella review of meta-analyses. PloS One 2018;13(3):e0194127.

3. Kalliala I, Markozannes G, Gunter MJ, et al. Obesity and gynaecological and obstetric conditions: umbrella review of the literature. BMJ 2017;359:j4511.

4. Collaboration PS. Body-mass index and cause-specific mortality in 900000 adults: collaborative analyses of 57 prospective studies. Lancet 2009;373(9669):1083-96.

5. Collaboration ERF. Separate and combined associations of body-mass index and abdominal adiposity with cardiovascular disease: collaborative analysis of 58 prospective studies. Lancet 2011;377(9771):1085-95.

6. Chen Y, Copeland WK, Vedanthan R, et al. Association between body mass index and cardiovascular disease mortality in east Asians and south Asians: pooled analysis of prospective data from the Asia Cohort Consortium. BMJ 2013;347:f5446.

7. Collaborators GO. Health effects of overweight and obesity in 195 countries over 25 years. N Engl J Med 2017;377(1):13-27.

8. Wang G, Zheng Z-J, Heath G, et al. Economic burden of cardiovascular disease associated with excess body weight in US adults. Am J Prev Med 2002;23(1):1-6.

9. Cappuccio FP, Miller MA. Cardiovascular disease and hypertension in sub-Saharan Africa: burden, risk and interventions. Intern Emerg Med 2016;11(3):299-305.

10. Emamgholipour S, Sari AA, Pakdaman M, et al. Economic Burden of Cardiovascular Disease in the Southwest of Iran. Int Cardiovasc Res J 2018;12(1)

11. Gaziano TA. Economic burden and the cost-effectiveness of treatment of cardiovascular diseases in Africa. Heart 2008;94(2):140-44.

12. Luengo-Fernandez R, Leal J, Gray A, et al. Cost of cardiovascular diseases in the United Kingdom. Heart 2006;92(10):1384-89.

13. Anand SS, Yusuf S. Stemming the global tsunami of cardiovascular disease. Lancet 2011;377(9765):529-32.

14. Lu Y, Hajifathalian K, Ezzati M, et al. Metabolic mediators of the effects of body-mass index, overweight, and obesity on coronary heart disease and stroke: a pooled analysis of 97 prospective cohorts with 1. 8 million participants. Lancet 2013;383(9921):970-83.

15. Larsson SC, Bäck M, Rees JM, et al. Body mass index and body composition in relation to 14 cardiovascular conditions in UK Biobank: a Mendelian randomization study. Eur Heart J 2020;41(2):221-26.

16. Lawlor DA, Hart CL, Hole DJ, et al. Reverse causality and confounding and the associations of overweight and obesity with mortality. Obesity 2006;14(12):2294-304.

17. Ioannidis JP. Why most discovered true associations are inflated. Epidemiology 2008:64048.

18. Dwan K, Gamble C, Williamson PR, et al. Systematic review of the empirical evidence of study publication bias and outcome reporting bias-an updated review. PloS One 2013;8(7):e66844.

19. Pereira TV, Ioannidis JP. Statistically significant meta-analyses of clinical trials have modest credibility and inflated effects. J Clin Epidemiol 2011;64(10):1060-69.

20. Li X, Meng X, Timofeeva M, et al. Serum uric acid levels and multiple health outcomes: umbrella review of evidence from observational studies, randomised controlled trials, and Mendelian randomisation studies. BMJ 2017;357:j2376. doi: 10.1136/bmj.j2376 [published Online First: 2017/06/09] 
21. Köhler CA, Evangelou E, Stubbs B, et al. Mapping risk factors for depression across the lifespan: An umbrella review of evidence from meta-analyses and Mendelian randomization studies. J Psychiatr Res 2018;103:189-207. doi: 10.1016/j.jpsychires.2018.05.020 [published Online First: 2018/06/11]

22. Moher D, Liberati A, Tetzlaff J, et al. Preferred reporting items for systematic reviews and meta-analyses: the PRISMA statement. Int J Surg 2010;8(5):336-41. doi: 10.1016/j.ijsu.2010.02.007 [published Online First: 2010/02/23]

23. Higgins J, Thompson SG. Quantifying heterogeneity in a meta $\square$ analysis. Stat Med 2002;21(11):1539-58.

24. Egger M, Smith GD. Bias in location and selection of studies. BMJ 1998;316(7124):61. 25. van Aert RCM, Wicherts JM, van Assen M. Publication bias examined in meta-analyses from psychology and medicine: A meta-meta-analysis. PloS One 2019;14(4):e0215052. doi: 10.1371/journal.pone.0215052 [published Online First: 2019/04/13]

26. van Assen MA, van Aert RC, Wicherts JM. Meta-analysis using effect size distributions of only statistically significant studies. Psychol Methods 2015;20(3):293-309. doi: 10.1037/met0000025 [published Online First: 2014/11/18]

27. Mertens G, Engelhard IM. A systematic review and meta-analysis of the evidence for unaware fear conditioning. Neurosci Biobehav Rev 2020;108:254-68. doi: 10.1016/j.neubiorev.2019.11.012 [published Online First: 2019/11/21]

28. Simonsohn U, Nelson LD, Simmons JP. p-Curve and Effect Size: Correcting for Publication Bias Using Only Significant Results. Perspect Psychol Sci 2014;9(6):666-81. doi: 10.1177/1745691614553988 [published Online First: 2015/07/18]

29. Higgins JP. Commentary: Heterogeneity in meta-analysis should be expected and appropriately quantified. Int J Epidemiol 2008;37(5):1158-60. doi: 10.1093/ije/dyn204 [published Online First: 2008/10/04]

30. Riley RD, Higgins JP, Deeks JJ. Interpretation of random effects meta-analyses. $B M J$ 2011;342:d549. doi: 10.1136/bmj.d549 [published Online First: 2011/02/12]

31. IntHout J, Ioannidis JP, Rovers MM, et al. Plea for routinely presenting prediction intervals in meta-analysis. BMJ Open 2016;6(7):e010247. doi: 10.1136/bmjopen-2015010247 [published Online First: 2016/07/14]

32. Higgins JP, Green S. Cochrane handbook for systematic reviews of interventions: John Wiley \& Sons 2011.

33. Choi EK, Park HB, Lee KH, et al. Body mass index and 20 specific cancers: re-analyses of dose-response meta-analyses of observational studies. Ann Oncol 2018;29(3):749-57. doi: 10.1093/annonc/mdx819 [published Online First: 2018/01/05]

34. Zhu J, Yu X, Zheng Y, et al. Association of glucose-lowering medications with cardiovascular outcomes: an umbrella review and evidence MAP. Lancet Diabetes Endocrinol 2020;8(3):192-205.

35. Piovani D, Danese S, Peyrin-Biroulet L, et al. Environmental Risk Factors for Inflammatory Bowel Diseases: An Umbrella Review of Meta-analyses. Gastroenterology 2019;157(3):647-59.e4. doi: 10.1053/j.gastro.2019.04.016 [published Online First: 2019/04/25]

36. Poole R, Kennedy OJ, Roderick P, et al. Coffee consumption and health: umbrella review of meta-analyses of multiple health outcomes. BMJ 2017;359

37. Neuenschwander M, Ballon A, Weber KS, et al. Role of diet in type 2 diabetes incidence: umbrella review of meta-analyses of prospective observational studies. BMJ 2019;366:12368.

38. Xu C, Niu Y, Wu J, et al. Software and package applicating for network meta $\square$ analysis: A usage $\square$ based comparative study. J Evid Based Med 2018;11(3):176-83. 
39. Kim A, Kim MS, Park YJ, et al. Clinical outcome of single-incision slings, excluding TVT-Secur, vs standard slings in the surgical management of stress incontinence: an updated systematic review and meta-analysis. BJUI 2019;123(4):566-84. doi: 10.1111/bju.14447 [published Online First: 2018/06/22]

40. Kim A, Kim MS, Park YJ, et al. Retropubic versus Transobturator Mid Urethral Slings in Patients at High Risk for Recurrent Stress Incontinence: A Systematic Review and MetaAnalysis. J Urol 2019;202(1):132-42. doi: 10.1097/ju.0000000000000222 [published Online First: 2019/03/14]

41. Oh Y, Kim MS, Lee YT, et al. Laparoscopic total gastrectomy as a valid procedure to treat gastric cancer option both in early and advanced stage: A systematic review and metaanalysis. Eur J Surg Oncol 2019

42. Jin HE, Kim MS, Lee CM, et al. Meta-analysis and systematic review on laparoscopicassisted distal gastrectomy (LADG) and totally laparoscopic distal gastrectomy (TLDG) for gastric cancer: Preliminary study for a multicenter prospective KLASS07 trial. Eur J Surg Oncol 2019;45(12):2231-40.

43. Fusar-Poli P, Radua J. Ten simple rules for conducting umbrella reviews. Evid Based Ment Health 2018;21(3):95-100. doi: 10.1136/ebmental-2018-300014 [published Online First: 2018/07/15]

44. Mongraw-Chaffin ML, Peters SA, Huxley RR, et al. The sex-specific association between BMI and coronary heart disease: a systematic review and meta-analysis of 95 cohorts with 1 . 2 million participants. Lancet Diabetes Endocrinol 2015;3(6):437-49.

45. Hemingway H, Philipson P, Chen R, et al. Evaluating the quality of research into a single prognostic biomarker: a systematic review and meta-analysis of 83 studies of C-reactive protein in stable coronary artery disease. PLoS Med 2010;7(6):e1000286. doi: 10.1371/journal.pmed.1000286 [published Online First: 2010/06/10]

46. Theodoratou E, Tzoulaki I, Zgaga L, et al. Vitamin D and multiple health outcomes: umbrella review of systematic reviews and meta-analyses of observational studies and randomised trials. BMJ 2014;348:g2035. doi: 10.1136/bmj.g2035 [published Online First: 2014/04/03]

47. Obesity: preventing and managing the global epidemic. Report of a WHO consultation. World Health Organ Tech Rep Ser 2000;894:i-xii, 1-253. [published Online First: 2001/03/10] 48. Brion MJ, Shakhbazov K, Visscher PM. Calculating statistical power in Mendelian randomization studies. Int $J$ Epidemiol 2013;42(5):1497-501. doi: 10.1093/ije/dyt179 [published Online First: 2013/10/26]

49. Wade KH, Davey Smith G. Adiposity and Cardiometabolic Outcomes: What Can Metaanalyses of Mendelian Randomization Studies Contribute? JAMA Netw Open 2018;1(7):e183778. doi: 10.1001/jamanetworkopen.2018.3778 [published Online First: 2019/01/16]

50. Riaz H, Khan MS, Siddiqi TJ, et al. Association Between Obesity and Cardiovascular Outcomes: A Systematic Review and Meta-analysis of Mendelian Randomization Studies. JAMA Netw Open 2018;1(7):e183788. doi: 10.1001/jamanetworkopen.2018.3788 [published Online First: 2019/01/16]

51. Bowden J, Holmes MV. Meta-analysis and Mendelian randomization: A review. Res Synth Methods 2019;10(4):486-96. doi: 10.1002/jrsm.1346 [published Online First: 2019/03/13]

52. Palmer TM, Thompson JR, Tobin MD. Meta-analysis of Mendelian randomization studies incorporating all three genotypes. Stat Med 2008;27(30):6570-82. doi: 10.1002/sim.3423 [published Online First: 2008/09/04] 
53. Casas JP, Bautista LE, Smeeth L, et al. Homocysteine and stroke: evidence on a causal link from mendelian randomisation. Lancet 2005;365(9455):224-32. doi: 10.1016/s01406736(05)17742-3 [published Online First: 2005/01/18]

54. Puhan MA, Schünemann HJ, Murad MH, et al. A GRADE Working Group approach for rating the quality of treatment effect estimates from network meta-analysis. BMJ 2014;349:g5630.

55. Khan SU, Khan MU, Riaz H, et al. Effects of nutritional supplements and dietary interventions on cardiovascular outcomes: an umbrella review and evidence map. Ann Intern Med 2019;171(3):190-98.

56. Shekelle PG, Maglione MA, Luoto J, et al. AHRQ Methods for Effective Health Care. Global Health Evidence Evaluation Framework. Rockville (MD): Agency for Healthcare Research and Quality (US) 2013.

57. Burns PB, Rohrich RJ, Chung KC. The levels of evidence and their role in evidencebased medicine. Plast Reconstr Surg 2011;128(1):305-10. doi: 10.1097/PRS.0b013e318219c171

58. Ho PM, Peterson PN, Masoudi FA. Evaluating the evidence: is there a rigid hierarchy? Circulation 2008;118(16):1675-84. doi: 10.1161/circulationaha.107.721357 [published Online First: 2008/10/15]

59. Katz DL, Karlsen MC, Chung M, et al. Hierarchies of evidence applied to lifestyle Medicine (HEALM): introduction of a strength-of-evidence approach based on a methodological systematic review. BMC Med Res Methodol 2019;19(1):178. doi: 10.1186/s12874-019-0811-z [published Online First: 2019/08/21]

60. Kim MS, Rhim HC, Park A, et al. Comparative efficacy and acceptability of pharmacological interventions for the treatment and prevention of delirium: A systematic review and network meta-analysis. J Psychiatr Res 2020

61. Alba AC, Alexander PE, Chang J, et al. High statistical heterogeneity is more frequent in meta-analysis of continuous than binary outcomes. J Clin Epidemiol 2016;70:129-35. doi: 10.1016/j.jclinepi.2015.09.005 [published Online First: 2015/09/20]

62. Bennett DA, Holmes MV. Mendelian randomisation in cardiovascular research: an introduction for clinicians. Heart 2017;103(18):1400-07. doi: 10.1136/heartjnl-2016-310605 [published Online First: 2017/06/10]

63. Pierce BL, Ahsan H, Vanderweele TJ. Power and instrument strength requirements for Mendelian randomization studies using multiple genetic variants. Int $J$ Epidemiol 2011;40(3):740-52. doi: 10.1093/ije/dyq151 [published Online First: 2010/09/04]

64. Shea BJ, Reeves BC, Wells G, et al. AMSTAR 2: a critical appraisal tool for systematic reviews that include randomised or non-randomised studies of healthcare interventions, or both. BMJ 2017;358:j4008. doi: 10.1136/bmj.j4008 [published Online First: 2017/09/25]

65. Wade KH, Carslake D, Sattar N, et al. BMI and mortality in UK Biobank: revised estimates using mendelian randomization. Obesity 2018;26(11):1796-806.

66. Khera AV, Chaffin M, Wade $\mathrm{KH}$, et al. Polygenic prediction of weight and obesity trajectories from birth to adulthood. Cell 2019;177(3):587-96. e9.

67. Haworth S, Mitchell R, Corbin L, et al. Common genetic variants and health outcomes appear geographically structured in the UK Biobank sample: Old concerns returning and their implications. BioRxiv 2018:294876.

68. Smith GD, Ebrahim S. Mendelian randomization: prospects, potentials, and limitations. Int J Epidemiol 2004;33(1):30-42.

69. Davies NM, Holmes MV, Davey Smith G. Reading Mendelian randomisation studies: a guide, glossary, and checklist for clinicians. BMJ 2018;362:k601. doi: 10.1136/bmj.k601 
70. Van Gaal LF, Mertens IL, Christophe E. Mechanisms linking obesity with cardiovascular disease. Nature 2006;444(7121):875-80.

71. Cachofeiro V, Miana M, Martín-Fernandez B, et al. Inflammation: a link between hypertension and atherosclerosis. Curr Hypertens Rev 2009;5(1):40-48.

72. Arnett DK, Blumenthal RS, Albert MA, et al. 2019 ACC/AHA Guideline on the Primary Prevention of Cardiovascular Disease. A Report of the American College of Cardiology/American Heart Association TaskForce on Clinical Practice Guidelines 2019;74(10):e177-e232. doi: 10.1016/j.jacc.2019.03.010

73. Schulz E, Gori T, Münzel T. Oxidative stress and endothelial dysfunction in hypertension. Hypertens Res 2011;34(6):665-73. doi: 10.1038/hr.2011.39 [published Online First: 2011/04/23]

74. Palla M, Saber H, Konda S, et al. Masked hypertension and cardiovascular outcomes: an updated systematic review and meta-analysis. Integr Blood Press Control 2018;11:11-24. doi: 10.2147/ibpc.s128947 [published Online First: 2018/01/31]

75. Thompson AM, Hu T, Eshelbrenner CL, et al. Antihypertensive treatment and secondary prevention of cardiovascular disease events among persons without hypertension: a metaanalysis. JAMA 2011;305(9):913-22. doi: 10.1001/jama.2011.250 [published Online First: 2011/03/03]

76. Li W, Zhao J, Song L, et al. Combined effects of carotid plaques and hypertension on the risk of cardiovascular disease and all-cause mortality. Clin Cardiol 2020 doi: 10.1002/clc.23372 [published Online First: 2020/05/14]

77. Rodriguez CJ, Swett K, Agarwal SK, et al. Systolic blood pressure levels among adults with hypertension and incident cardiovascular events: the atherosclerosis risk in communities study. JAMA Intern Med 2014;174(8):1252-61. doi: 10.1001/jamainternmed.2014.2482 [published Online First: 2014/06/18]

78. Holmes MV, Lange LA, Palmer T, et al. Causal effects of body mass index on cardiometabolic traits and events: a Mendelian randomization analysis. Am J Hum Genet 2014;94(2):198-208.

79. Lyall DM, Celis-Morales C, Ward J, et al. Association of body mass index with cardiometabolic disease in the UK Biobank: a Mendelian randomization study. JAMA Cardiol 2017;2(8):882-89.

80. Fall T, Hägg S, Mägi R, et al. European Network for Genetic and Genomic Epidemiology (ENGAGE) consortium. The role of adiposity in cardiometabolic traits: a Mendelian randomization analysis. PLoS Med 2013;10(6):e1001474.

81. Boden-Albala B, Sacco RL. Lifestyle factors and stroke risk: Exercise, alcohol, diet, obesity, smoking, drug use, and stress. Curr Atheroscler Rep 2000;2(2):160-66. doi: 10.1007/s11883-000-0111-3

82. van Vliet-Ostaptchouk JV, Snieder H, Lagou V. Gene-Lifestyle Interactions in Obesity. Curr Nutr Rep 2012;1(3):184-96. doi: 10.1007/s13668-012-0022-2 [published Online First: 2012/01/01]

83. Jääskeläinen $T$, Paananen $J$, Lindström $J$, et al. Genetic predisposition to obesity and lifestyle factors--the combined analyses of twenty-six known BMI- and fourteen known waist:hip ratio (WHR)-associated variants in the Finnish Diabetes Prevention Study. The Br J Nutr 2013;110(10):1856-65. doi: 10.1017/s0007114513001116 [published Online First: 2013/05/15]

84. Day FR, Loos RJ. Developments in obesity genetics in the era of genome-wide association studies. J Nutrigenet Nutrigenomics 2011;4(4):222-38. doi: 10.1159/000332158 [published Online First: 2011/11/08] 
medRxiv preprint doi: https://doi.org/10.1101/2020.08.18.20176578; this version posted August 22, 2020. The copyright holder for this preprint (which was not certified by peer review) is the author/funder, who has granted medRxiv a license to display the preprint in perpetuity.

It is made available under a CC-BY-NC-ND 4.0 International license .

85. Eckel RH, Krauss RM. American Heart Association call to action: obesity as a major risk factor for coronary heart disease. AHA Nutrition Committee. Circulation 1998;97(21):2099100. doi: 10.1161/01.cir.97.21.2099 [published Online First: 1998/06/17]

86. Ghanta RK, LaPar DJ, Zhang Q, et al. Obesity Increases Risk-Adjusted Morbidity, Mortality, and Cost Following Cardiac Surgery. J Am Heart Assoc 2017;6(3) doi: 10.1161/jaha.116.003831 [published Online First: 2017/03/10]

87. Zhou X, Yu J, Li L, et al. Effects of Bariatric Surgery on Mortality, Cardiovascular Events, and Cancer Outcomes in Obese Patients: Systematic Review and Meta-analysis. Obes Surg 2016;26(11):2590-601. doi: 10.1007/s11695-016-2144-x [published Online First: 2016/10/21] 88. Carter AR, Gill D, Davies NM, et al. Understanding the consequences of education inequality on cardiovascular disease: mendelian randomisation study. BMJ 2019;365:11855. doi: 10.1136/bmj.11855

89. Ge L, Sadeghirad B, Ball GDC, et al. Comparison of dietary macronutrient patterns of 14 popular named dietary programmes for weight and cardiovascular risk factor reduction in adults: systematic review and network meta-analysis of randomised trials. $B M J$ 2020;369:m696. doi: 10.1136/bmj.m696 [published Online First: 2020/04/03]

90. Ho FK, Gray SR, Welsh P, et al. Associations of fat and carbohydrate intake with cardiovascular disease and mortality: prospective cohort study of UK Biobank participants. BMJ 2020;368:m688. doi: 10.1136/bmj.m688

91. Drouin-Chartier J-P, Chen S, Li Y, et al. Egg consumption and risk of cardiovascular disease: three large prospective US cohort studies, systematic review, and updated metaanalysis. BMJ 2020;368:m513. doi: 10.1136/bmj.m513

92. Li Z-H, Zhong W-F, Liu S, et al. Associations of habitual fish oil supplementation with cardiovascular outcomes and all cause mortality: evidence from a large population based cohort study. BMJ 2020;368:m456. doi: 10.1136/bmj.m456

93. Mozaffarian D, Hao T, Rimm EB, et al. Changes in diet and lifestyle and long-term weight gain in women and men. N Engl J Med 2011;364(25):2392-404.

94. Sun Y, Liu B, Snetselaar LG, et al. Association of fried food consumption with all cause, cardiovascular, and cancer mortality: prospective cohort study. BMJ 2019;364:k5420. doi: 10.1136/bmj.k5420

95. Li Y, Schoufour J, Wang DD, et al. Healthy lifestyle and life expectancy free of cancer, cardiovascular disease, and type 2 diabetes: prospective cohort study. BMJ 2020;368:16669. doi: $10.1136 / \mathrm{bmj} .16669$

96. Lichtenstein AH, Appel LJ, Brands M, et al. Summary of American Heart Association Diet and Lifestyle Recommendations revision 2006. Arterioscler Thromb Vasc Biol 2006;26(10):2186-91. doi: 10.1161/01.ATV.0000238352.25222.5e [published Online First: 2006/09/23]

\section{Figure legends}


Fig. 1. Flow diagram of the search and selection process

Fig. 2. Collective results from observational studies. (A) Increased risk of cardiovascular events with elevated continuous and categorical BMI. (B) Increased risk of death with elevated continuous BMI. All results are based on random-effect models. The cohort and participant columns display the number of independent cohorts and the total number of participants incorporated in the meta-analysis for the outcome. The certainty of evidence underlying each association between BMI and cardiovascular outcomes was evaluated with the GRADE framework. GRADE, Grading of Recommendations Assessment, Development, and Evaluation; BMI, Body mass index; RR, Risk ratio or relative risk

Fig. 3. Collective results from Mendelian randomisation studies. (A) Increased risk of cardiovascular events per $1 \mathrm{~kg} / \mathrm{m}^{2}$ increase in BMI. (B) Increased risk of cardiovascular events per $5 \mathrm{~kg} / \mathrm{m}^{2}$ increase in BMI. (C) Increased risk of death per $1 \mathrm{~kg} / \mathrm{m}^{2}$ increase in BMI. All results are based on random-effects models. The cohort and cases columns display the number of independent cohorts and the number of cases incorporated in the meta-analysis for the outcome. BMI, Body mass index; RR, Risk ratio or relative risk

Fig. 4. (A) Dose-response relationship of the incidence of cardiovascular events with step-up in categorical BMI. (B) Subgroup analysis for sex. All results are based on random-effects models. The cohort and participant columns display the number of independent cohorts and the total number of participants incorporated in the meta-analysis for the outcome. The certainty of evidence was evaluated with the GRADE framework. GRADE, Grading of Recommendations Assessment, Development, and Evaluation; BMI, Body mass index; RR, Risk ratio or relative risk 
Table 1. Evidence map for appraisal of the certainty of evidence for the association between obesity and cardiovascular outcomes in each population

\begin{tabular}{|c|c|c|c|}
\hline \multirow{2}{*}{$\begin{array}{l}\text { GRADE } \\
\text { (certainty of } \\
\text { evidence) }\end{array}$} & \multicolumn{3}{|c|}{ Health risk of obesity in; } \\
\hline & Overall population & Men & Women \\
\hline High* & $\begin{array}{l}\text { All-cause mortality (severely obese), All-cause } \\
\text { mortality (overweight), All-cause mortality (never- } \\
\text { smokers), Case-specific mortality (per } 5 \text { units for } \\
\text { CVD, CHD, and stroke), Pulmonary embolism } \\
\text { (obese) }\end{array}$ & $\begin{array}{l}\text { All-cause mortality (per } 5 \text { units), Coronary heart } \\
\text { disease (per } 1 \text { units), Heart failure (per } 5 \text { units), } \\
\text { Heart failure (WC per } 10 \mathrm{~cm} \text { ) }\end{array}$ & $\begin{array}{l}\text { All-cause mortality (per } 5 \text { units), Coronary heart } \\
\text { disease (overweight), Coronary heart disease (per } 1 \\
\text { units) }\end{array}$ \\
\hline Moderate* & $\begin{array}{l}\text { Sudden cardiac death (overweight and obese), All- } \\
\text { cause mortality (obese), Coronary heart disease } \\
\text { (obese), Coronary heart disease (per } 5 \text { units), } \\
\text { Hypertension (WC and WHR per } 10 \mathrm{~cm} \text { and } 0.1 \text { unit, } \\
\text { respectively), Heart failure (per } 5 \text { units), Heart failure } \\
\text { (WC per } 10 \mathrm{~cm} \text { ), Heart failure (overweight), Atrial } \\
\text { fibrillation (WC and WHR per } 10 \mathrm{~cm} \text { and } 0.1 \text { unit, } \\
\text { respectively), Aortic valve stenosis (obese), Aortic } \\
\text { valve stenosis (WC per } 10 \mathrm{~cm} \text { ) }\end{array}$ & $\begin{array}{l}\text { Coronary heart disease (overweight and obese), } \\
\text { Atrial fibrillation (per } 5 \text { units) }\end{array}$ & $\begin{array}{l}\text { Coronary heart disease (obese), Heart failure (WC } \\
\text { per } 10 \mathrm{~cm} \text { ) }\end{array}$ \\
\hline Low* & $\begin{array}{l}\text { Hypertension (per } 5 \text { units), All-cause mortality (per } 5 \\
\text { units), Coronary heart disease (overweight), Heart } \\
\text { failure (obese and severely obese), Heart failure } \\
\text { (WHR per } 0.1 \text { unit), Stroke (per } 5 \text { units), Stroke } \\
\text { (obese), Aortic valve stenosis (overweight), venous } \\
\text { thromboembolism (obese) }\end{array}$ & Hypertension (per 5 unit) & $\begin{array}{l}\text { Heart failure (per } 5 \text { units), Atrial fibrillation (per } 5 \\
\text { units) }\end{array}$ \\
\hline Very low* & $\begin{array}{l}\text { Atrial fibrillation (per } 5 \text { units), Atrial fibrillation } \\
\text { (obese) }\end{array}$ & & Hypertension (per 5 unit) \\
\hline Not significant & $\begin{array}{l}\text { Stroke (overweight, high), Heart failure mortality } \\
\text { (per } 5 \text { units, very low) }\end{array}$ & Heart failure (WHR per 0.1 unit, low) & Heart failure (WHR per 0.1 unit, low) \\
\hline
\end{tabular}

Obese and overweight populations were compared to the normal population (BMI, 18.5-25). *High, moderate, low, and very low include outcomes with statistical significance ( $\mathrm{p}<0.05$ ).

Per 5 units: Increased risk per $5 \mathrm{~kg} / \mathrm{m}^{2}$ (BMI), WC: Waist circumference, WHR: Waist-to-hip ratio, CHD: Coronary heart disease, CVD: Cardiovascular disease (include CHD and stroke)

GRADE (Grading of Recommendations, Assessment, Development and Evaluation):

High: This evidence provides a very good indication of the likely effect. The likelihood that the effect will be substantially different is low.

Moderate: This evidence provides a good indication of the likely effect. The likelihood that the effect will be substantially different is moderate.

Low: This evidence provides some indication of the likely effect. However, the likelihood that it will be substantially different (a large enough difference that it might have an effect on a decision) is high.

Very low: This evidence does not provide a reliable indication of the likely effect. The likelihood that the effect will be substantially different (a large enough difference that it might have an effect on a decision) is very high. 
Table 2. Evidence map for appraisal of the certainty of evidence for the association between obesity and each cardiovascular outcome

\begin{tabular}{|c|c|c|c|c|c|c|}
\hline Main outcomes & BMI categorical & $\begin{array}{l}\text { BMI continuous } \\
\left(\text { per } 5 \mathrm{~kg} / \mathrm{m}^{2}\right)\end{array}$ & WC & WHR & $\begin{array}{l}\text { Concordance } \\
\text { (between observational } \\
\text { study and MR) }\end{array}$ & Summary of evidence \\
\hline \multicolumn{7}{|l|}{ Mortality } \\
\hline All-cause mortality & $\begin{array}{l}\text { High for overweight } \\
\text { Moderate for obese } \\
\text { High for severely obese }\end{array}$ & $\begin{array}{l}\text { High for non-smokers } \\
\text { Low for all population }\end{array}$ & - & - & No (not significant in MR) & $\begin{array}{l}\text { High in general, without causality } \\
\text { supported by MR. Requires cautious } \\
\text { interpretation }\end{array}$ \\
\hline Heart failure & - & Not significant (very low) & - & - & MR not reported & Very low \\
\hline Coronary heart disease & - & High & - & - & Yes & High, with causality supported by MR \\
\hline Cardiovascular disease & - & High & - & - & Yes & High, with causality supported by MR \\
\hline Stroke & - & High & - & - & No (not significant in MR) & $\begin{array}{l}\text { High, without causality supported by } \\
\text { MR. Requires cautious interpretation }\end{array}$ \\
\hline Sudden cardiac death & $\begin{array}{l}\text { Moderate for overweight } \\
\text { Moderate for obese }\end{array}$ & - & - & - & MR not reported & Moderate \\
\hline \multicolumn{7}{|l|}{ Incidence } \\
\hline Coronary heart disease & $\begin{array}{l}\text { Low for overweight } \\
\text { Moderate for obese }\end{array}$ & Moderate & - & - & Yes & $\begin{array}{l}\text { Moderate in general, with causality } \\
\text { supported by MR }\end{array}$ \\
\hline Stroke & $\begin{array}{l}\text { Not significant for overweight (high) } \\
\text { Low for obese }\end{array}$ & Low & - & - & $\begin{array}{l}\text { Partially yes } \$ \\
\text { (not significant in MR) }\end{array}$ & $\begin{array}{l}\text { Low, without causality supported by } \\
\text { MR }\end{array}$ \\
\hline Heart failure & $\begin{array}{l}\text { Moderate for overweight } \\
\text { Low for obese } \\
\text { Low for severely obese }\end{array}$ & Moderate & Moderate & Low & Yes & $\begin{array}{l}\text { Low to moderate, with causality } \\
\text { supported by MR }\end{array}$ \\
\hline Atrial fibrillation & Very low for obese & Very low & Moderate & Moderate & Yes & $\begin{array}{l}\text { Very low for BMI and moderate for } \\
\text { WC \& WHR, with causality } \\
\text { supported by MR }\end{array}$ \\
\hline Aortic valve stenosis & $\begin{array}{l}\text { Low for overweight } \\
\text { Moderate for obese }\end{array}$ & - & Moderate & - & Yes & $\begin{array}{l}\text { Moderate in general, with causality } \\
\text { supported by MR }\end{array}$ \\
\hline Hypertension & - & Low & Moderate & Moderate & Yes & $\begin{array}{l}\text { Moderate in general, with causality } \\
\text { supported by MR }\end{array}$ \\
\hline Pulmonary embolism & High for obese & - & - & - & Yes & High, with causality supported by MR \\
\hline $\begin{array}{l}\text { Venous } \\
\text { thromboembolism }\end{array}$ & Low for obese & - & - & - & Yes & Low, with causality supported by MR \\
\hline
\end{tabular}

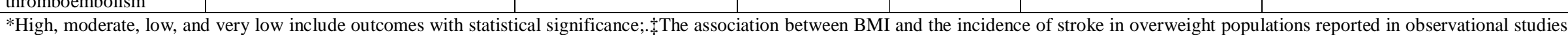

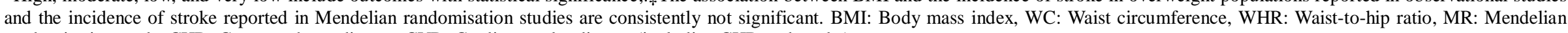
randomisation study, CHD: Coronary heart disease, CVD: Cardiovascular disease (including CHD and stroke) 
medRxiv preprint doi: https://doi.org/10.1101/2020.08.18.20176578; this version posted August 22, 2020. The copyright holder for this preprint (which was not certified by peer review) is the author/funder, who has granted medRxiv a license to display the preprint in perpetuity.

It is made available under a CC-BY-NC-ND 4.0 International license .

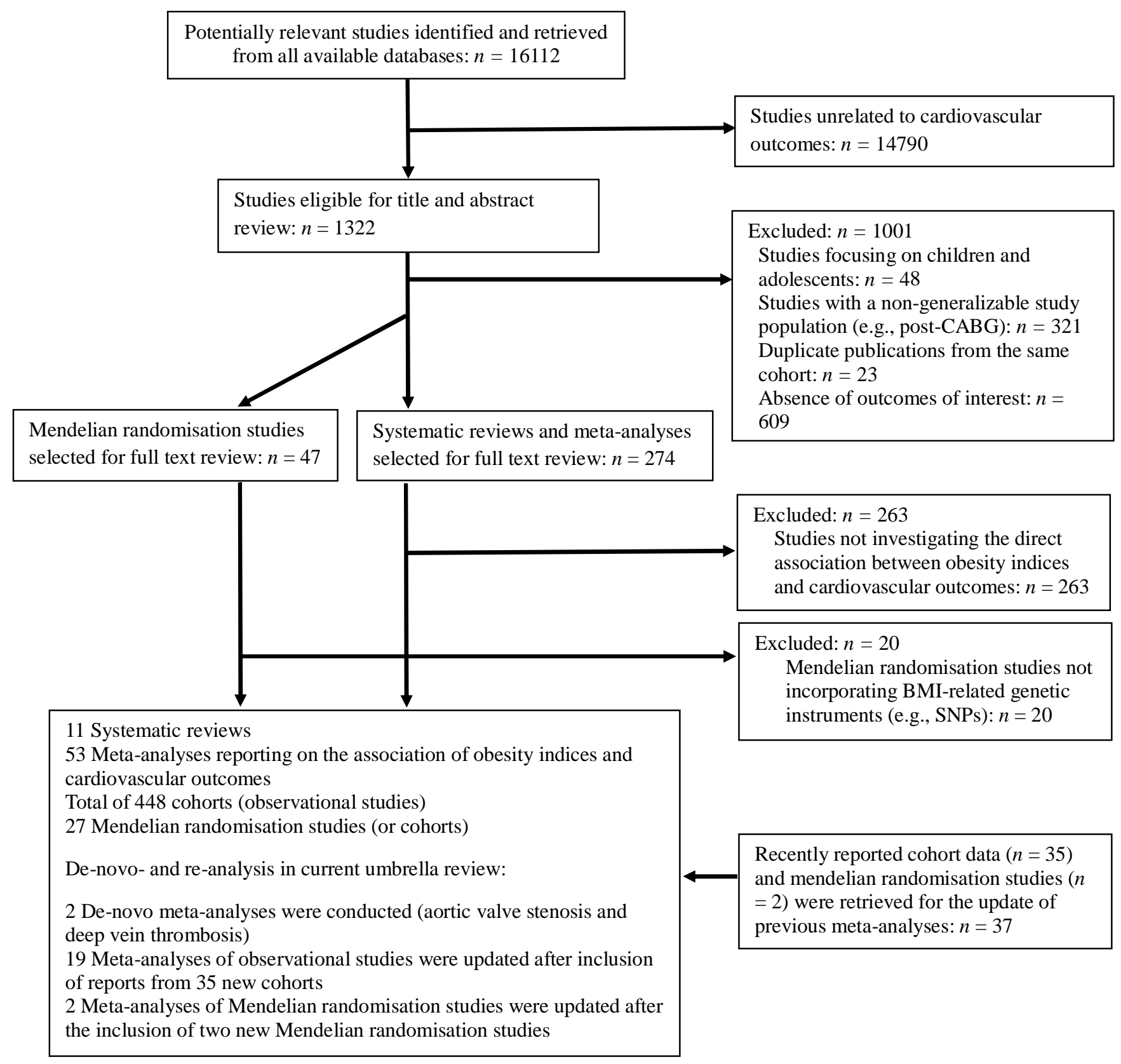

Fig. 1. Flow diagram of the search and selection process 
A. Incidence: Observational studies

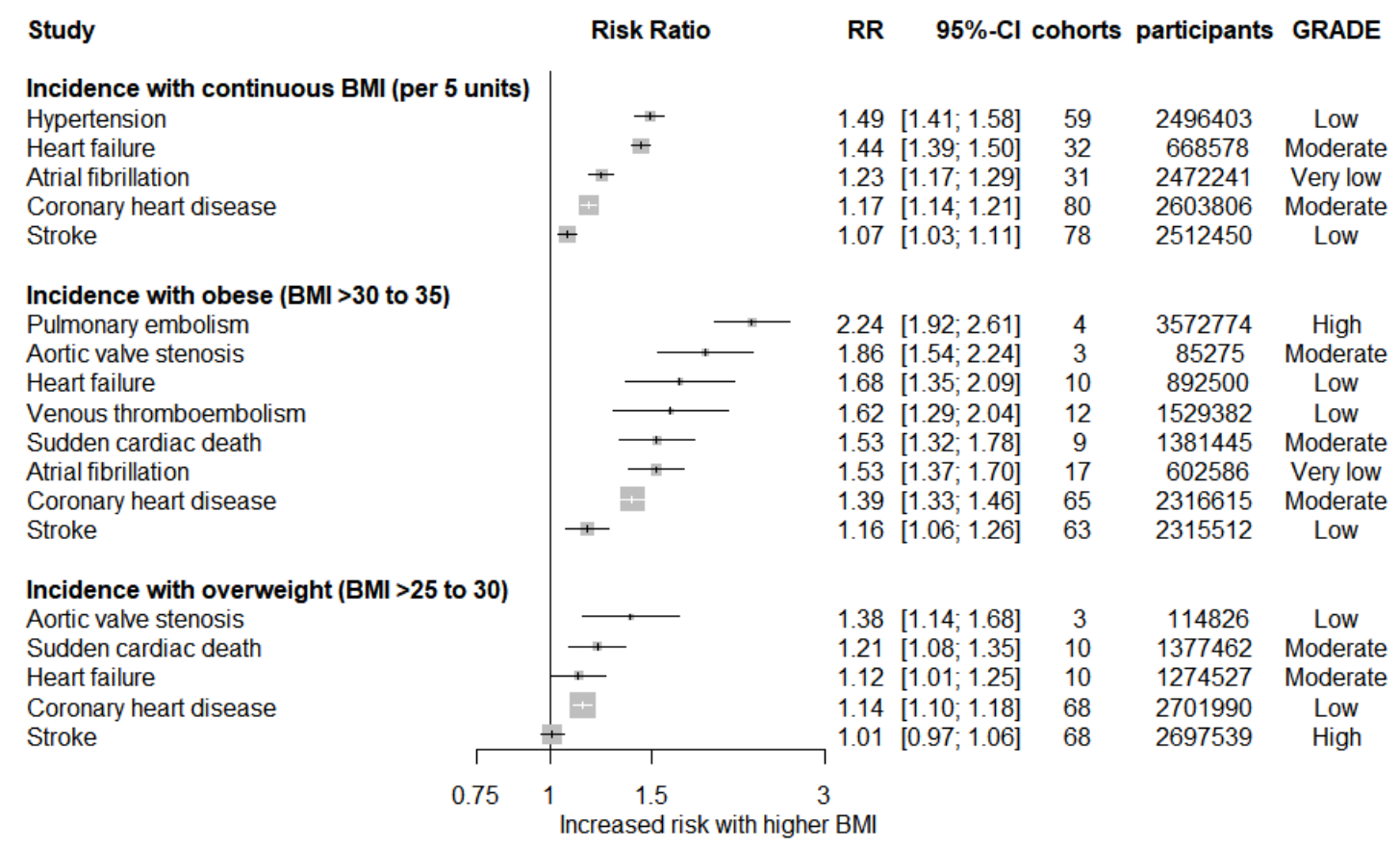

B. Mortality: Observational studies

\begin{tabular}{|c|c|c|c|c|c|c|}
\hline Study & Risk Ratio & $\mathbf{R R}$ & $95 \%-\mathrm{Cl}$ & cohorts & participants & GRADE \\
\hline \multicolumn{7}{|l|}{ Mortality with continuous BMI (per 5 units) } \\
\hline Cardiovascular disease & $\mp$ & 1.49 & {$[1.45 ; 1.53]$} & 164 & 1483133 & High \\
\hline Coronary heart disease & $\rightarrow$ & 1.42 & {$[1.35 ; 1.49]$} & 124 & 1550175 & High \\
\hline Stroke & $\rightarrow$ & 1.42 & {$[1.35 ; 1.50]$} & 114 & 1530488 & High \\
\hline All-cause mortality (never-smoker) & + & 1.31 & {$[1.29 ; 1.33]$} & 189 & 1691813 & High \\
\hline All-cause mortality (overall population) & + & 1.05 & {$[1.04 ; 1.07]$} & 200 & 34201311 & Low \\
\hline 0.75 & 1 & 2 & & & & \\
\hline
\end{tabular}

Fig. 2. Collective results from observational studies. (A) Increased risk of cardiovascular events with elevated continuous and categorical BMI. (B) Increased risk of death with elevated continuous BMI. All results are based on random-effect models. The cohort and participant columns display the number of independent cohorts and the total number of participants incorporated in the meta-analysis for the outcome. The certainty of evidence underlying each association between BMI and cardiovascular outcomes was evaluated with the GRADE framework. GRADE, Grading of Recommendations Assessment, Development, and Evaluation; BMI, Body mass index; RR, Risk ratio or relative risk 
medRxiv preprint doi: https://doi.org/10.1101/2020.08.18.20176578; this version posted August 22, 2020. The copyright holder for this preprint (which was not certified by peer review) is the author/funder, who has granted medRxiv a license to display the preprint in perpetuity.

It is made available under a CC-BY-NC-ND 4.0 International license .

A. Incidence $\left(\right.$ per $1 \mathrm{~kg} / \mathrm{m}^{2}$ ): Mendelian randomisation studies

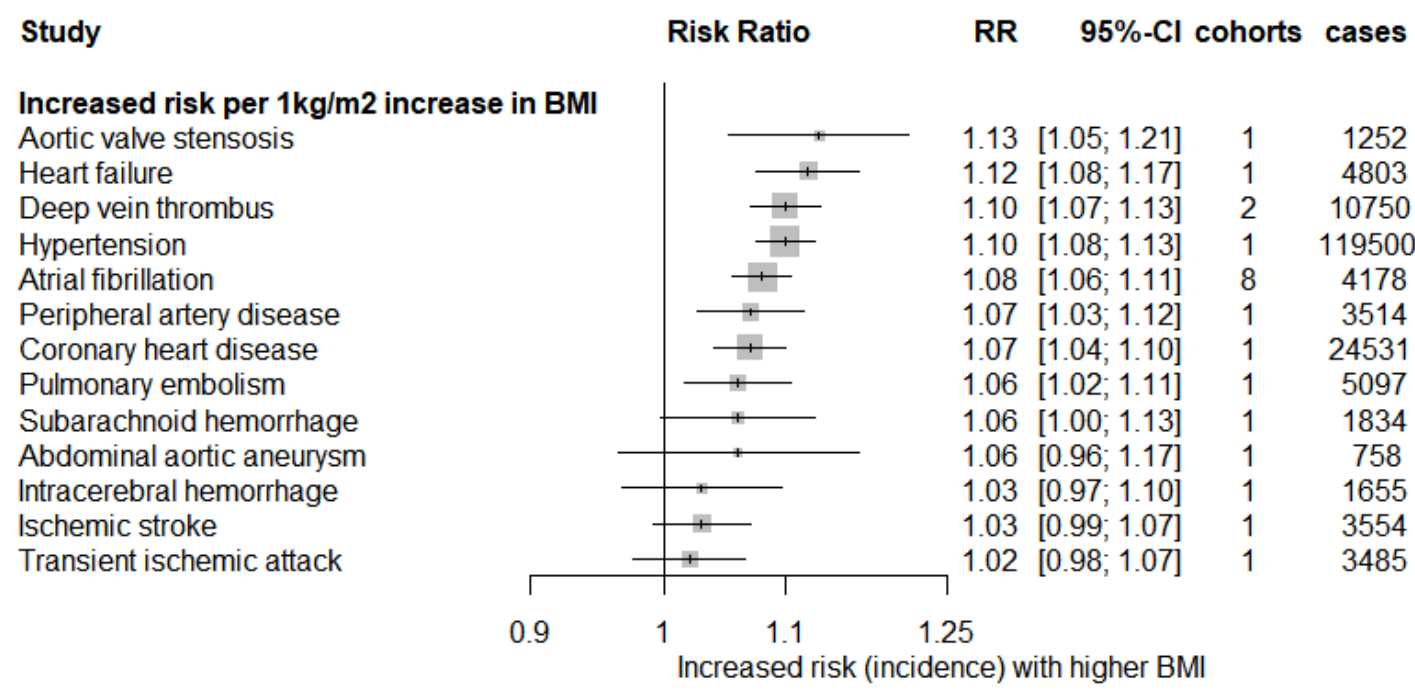

B. Incidence (per $5 \mathrm{~kg} / \mathrm{m}^{2}$ ): Mendelian randomisation studies

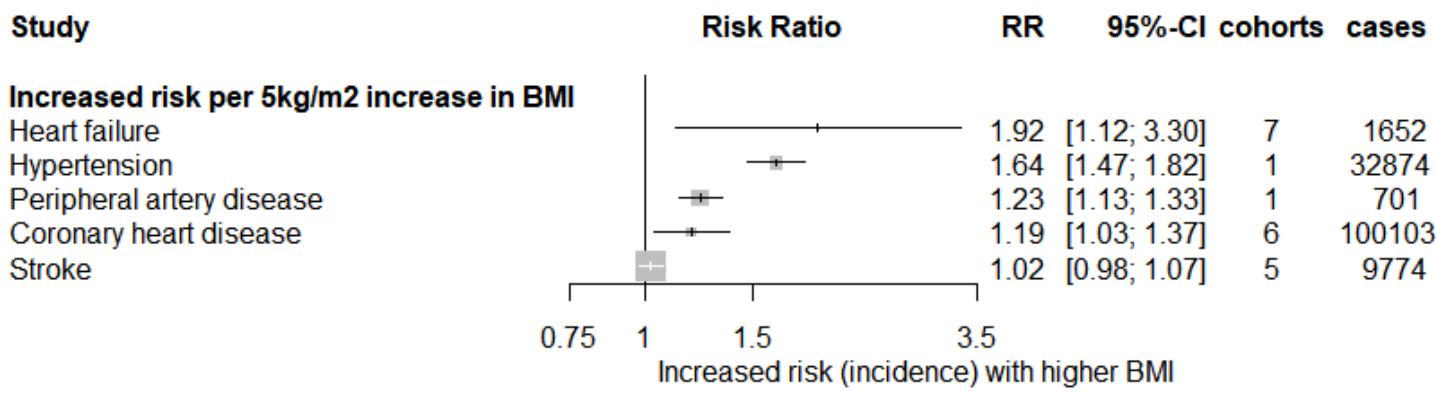

C. Mortality: Mendelian randomisation studies

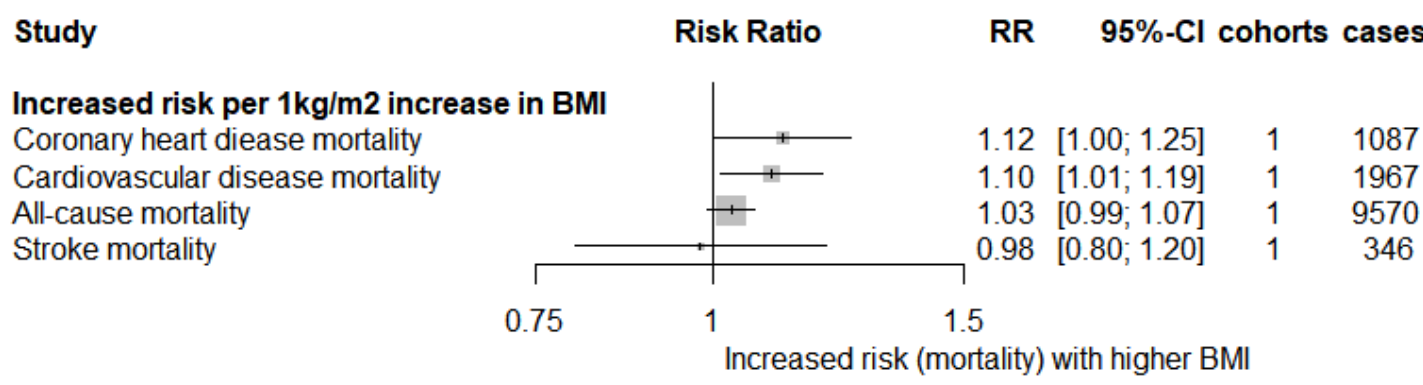

Fig. 3. Collective results from Mendelian randomisation studies. (A) Increased risk of cardiovascular events per $1 \mathrm{~kg} / \mathrm{m}^{2}$ increase in BMI. (B) Increased risk of cardiovascular events per $5 \mathrm{~kg} / \mathrm{m}^{2}$ increase in BMI. (C) Increased risk of death per $1 \mathrm{~kg} / \mathrm{m}^{2}$ increase in BMI. All results are based on random-effects models. The cohort and cases columns display the number of independent cohorts and the number of cases incorporated in the meta-analysis for 
the outcome. BMI, Body mass index; RR, Risk ratio or relative risk

A. Dose-response association analysis

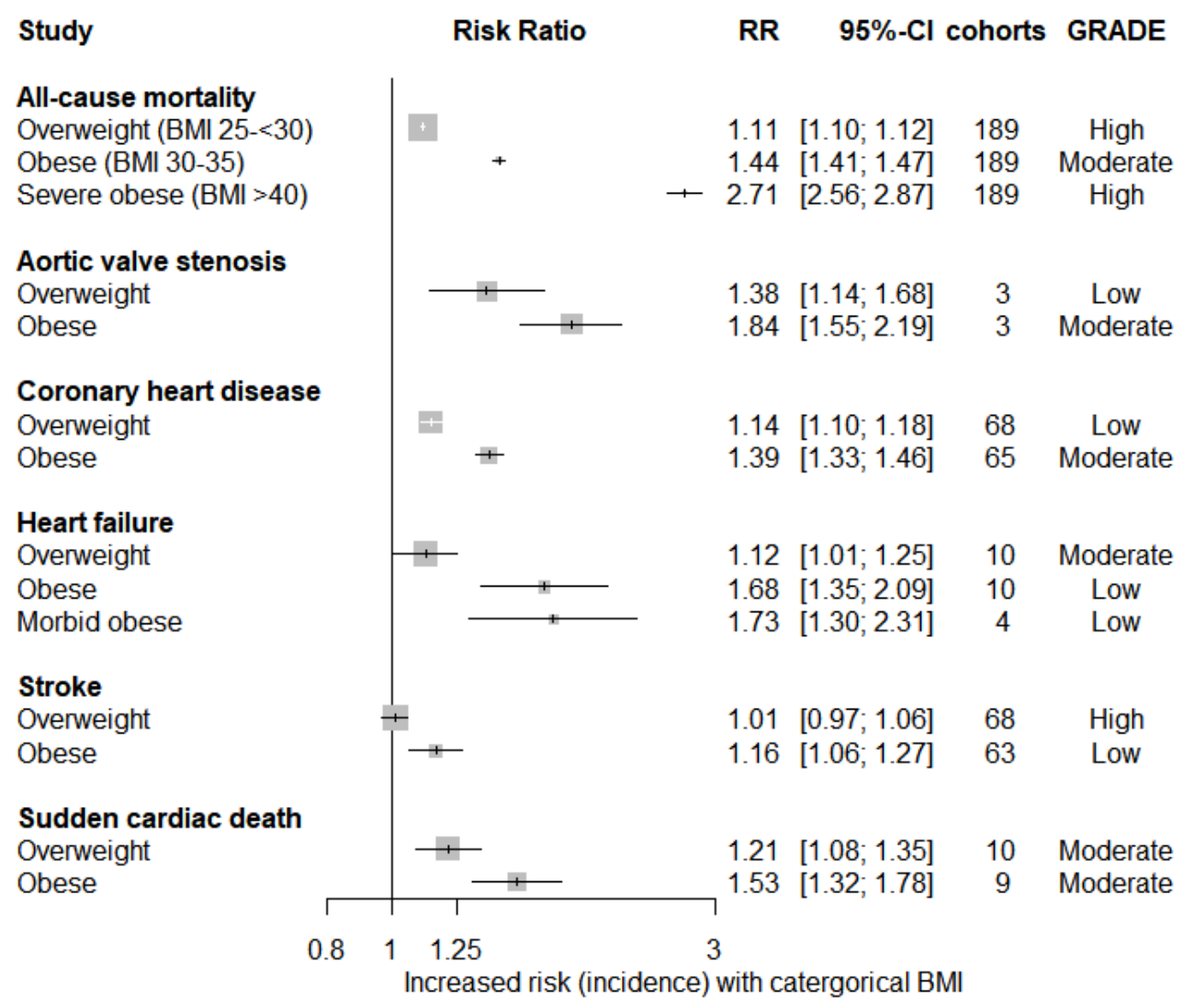

B. Sex subgroup analysis

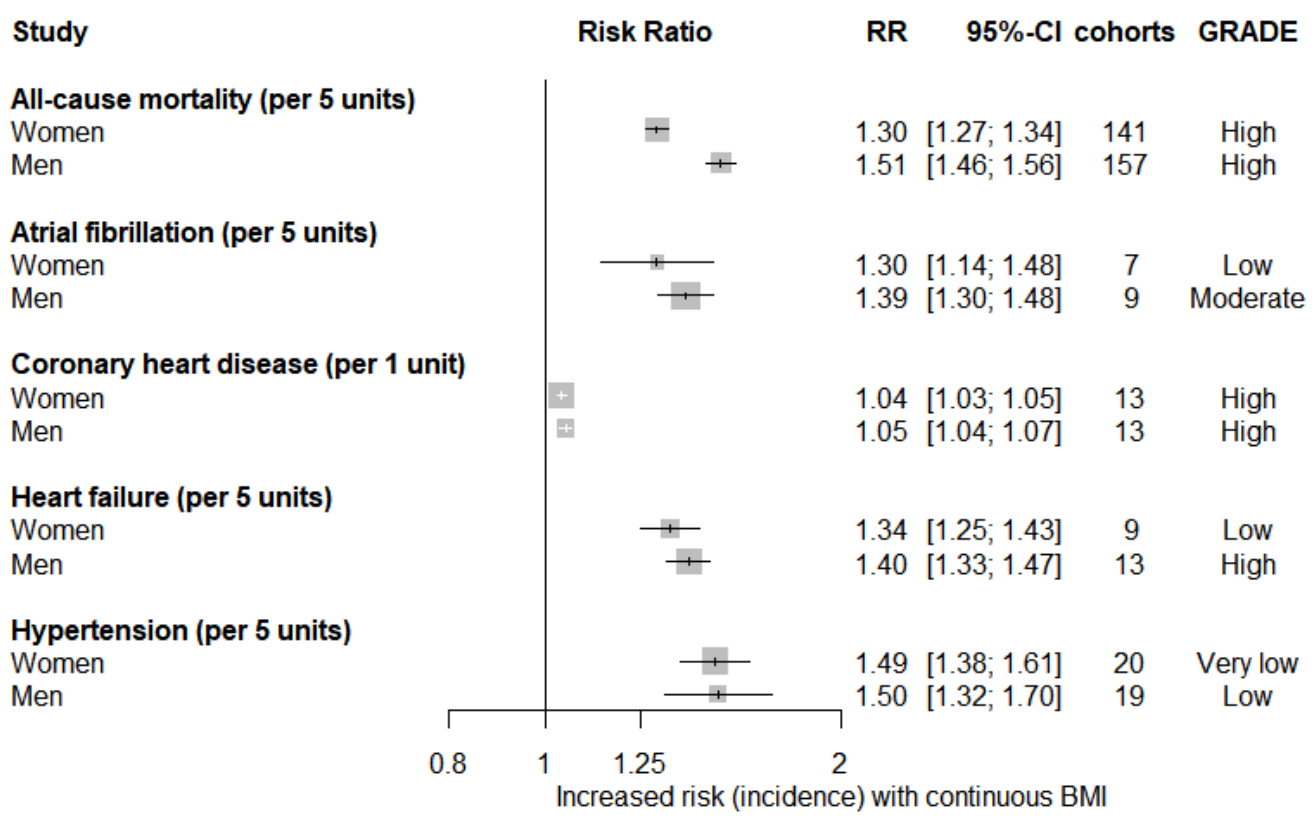


Fig. 4. (A) Dose-response relationship of the incidence of cardiovascular events with step-up in categorical BMI. (B) Subgroup analysis for sex. All results are based on random-effects models. The cohort and participant columns display the number of independent cohorts and the total number of participants incorporated in the meta-analysis for the outcome. The certainty of evidence was evaluated with the GRADE framework. GRADE, Grading of Recommendations Assessment, Development, and Evaluation; BMI, Body mass index; RR, Risk ratio or relative risk 